\title{
The Overview and Tendency of Corporate Environmental Responsibility in the Construction Industry of China
}

\author{
Ying Jiang ${ }^{1, a}$, Xiaolong Xue ${ }^{1,2}$ \\ ${ }^{1}$ School of Management, Harbin Institute of Technology, Harbin, China, 150001. \\ ${ }^{2}$ School of Management, Guangzhou University, Guangzhou, China, 510006.
}

\begin{abstract}
Although the research on the corporate social responsibility (CSR) has attached increasing attention in recent years, the definition and measurement of CSR in the construction industry are still not sufficient. This paper reviewed previous literatures on the definition and measurement of CSR. Then, the study defined and constructed the index of corporate social responsibility in the construction industry based on the classic theory of triple bottom line and stakeholder theory. At last, the study put forward the further research of CSR in the construction industry of China.
\end{abstract}

\section{Introduction}

Construction industry is explained as the production sector that is specialized in civil engineering, housing construction, equipment installation and engineering survey and design work of the engineering survey. Construction industry, different from manufacturing industry, has the similar production process but different types of products. Its products include all kinds of factories, mines, railways, bridges, port, roads, pipelines, house, public facilities etc. Construction industry plays an important role on the national economy and people's livelihood and social development. However, it has an negative effect on the life of the people and natural environment including resource depletion, land degradation, waste generation and various forms of pollution (Lu et al. 2016). Because of the damage of construction activities to physical environment and contractors' reactive attitudes towards CER, construction industry has become one of the focuses of government and environmentalists (Jiang and Wong 2016). Even in the developed countries, CER system is lack of adequacy at explaining how construction firms to implement environmental responsibilities (Loosemore and Lim 2018).

With the development of economy and society in China, the contradiction between environmental protection and economic performance increasingly intensifies. Some construction firms neglect CER in order to seek to maximize profits. Under the demand of global sustainable development, the development of economy can no longer ignore the environmental impact and destruction. Each firm must assume CER in all industries including construction industry. While, there has been little research on CER in construction industry of China. In order to address the gap, the paper aims at showing the current situation of CER in construction

a Corresponding author: jiang89120506@163.com industry of China, analyzing the dilemma and proposing the advices that enhance CER practice in construction industry of China.

The rest of the manuscript is organized as the following: The second section, the study explores the current situation of CER in construction industry of China; The third section, the paper analyzes the dilemma on CER in construction industry of China; The forth section, we propose the some advices on improving CER of construction industry of China.

\section{The current situation of CER in the construction industry}

The process of building production in construction industry has the characteristic of disposable, complexity, fixed production location, numerous participating parties, large products and long production cycle. In the construction cycle, a large amount of resources are consumed, a lot of noises and pollution are produced and the surrounding environment is destroyed. Energy consumption in construction industry accounts for $40 \%$ of the global energy consumption and 1/3 global greenhouse gas emissions originates from construction industry (Lu et al. 2016). It is not optimistic to CER practice even in the developed counties. Loosemore and Lim (2018) had a survey of 104 firms from across the construction and engineering industry from New Zealand and Australia and found that CER in the construction and engineering industry is largely informal, reactive and in its early stages of development.

In the global context of sustainable development, China's construction industry is currently standing at a special and crucial period (Shen et al. 2011).

At present, it is still voluntary to pubilsh CSR reports in China. According to "CSR Blue Book 2016" released by the Chinese Academy of Social Science, as is shown 
in Figure 1, index of CER in construction industry is inclined to an undulant ascend from 2012 to 2015. The index of CER in construction industry is in the decline, which means that the construction's of CER is still weak. Environmental protection has arisen widespread concern since the haze erupted throughout the country in 2013. Thus, instruction firms have improved CER practice and the index of CER has been inclined to upgrade.

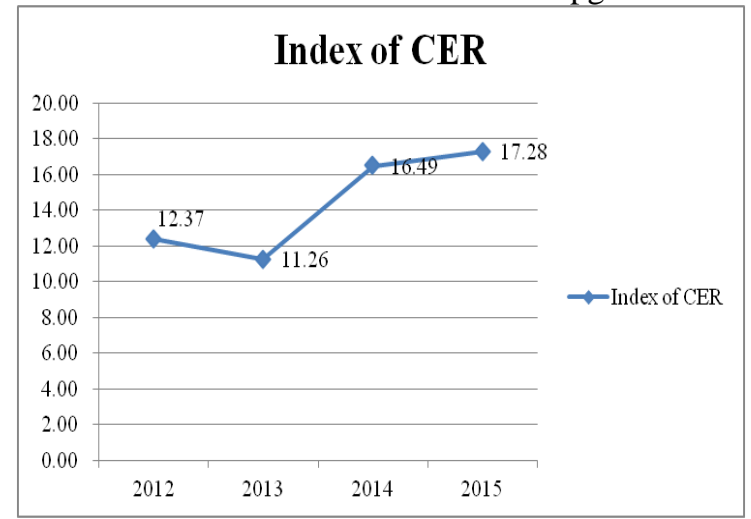

Figure 1 Index of CER in Construction Industry

Figure 2 shows that there are in different levels between CER practice of listed companies and CER practice of non-listed companies. On the whole, nonlisted firm's index of CER is obviously lower than listed firm's index. It means that listed firms are engaged in more CER than non-listed firms in the construction industry.

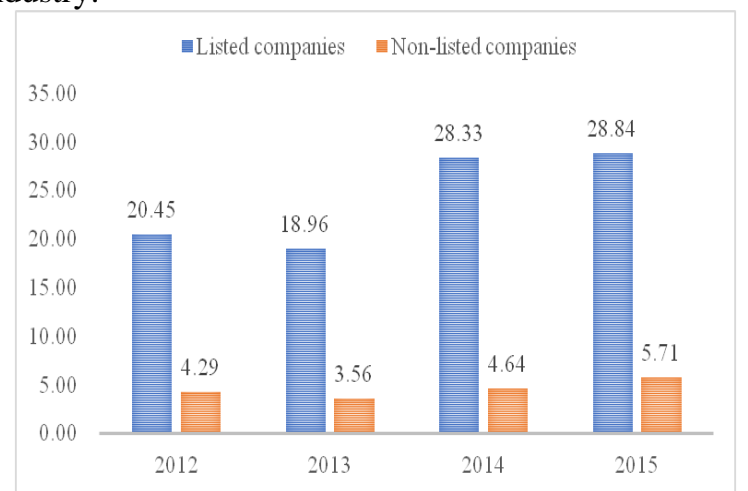

Figure 2 Index of CER's Comparison between Listed Company and Non-listed Company Construction industry

Although the index of CER in the construction industry demonstrates an upgrade tendency, but the creditability of the result is worrying. Golden bee company categorizes the quality of CSR reports into six dimensions including substantiality, completeness, creditability, innovativeness, comparability and readability. Just is shown in Figure 3, among the six dimensions, the average scoring rate on creditability and innovativeness of CSR reports in the construction industry are obviously lower than other dimensions in 2017. Further, the average scoring rate on creditability and innovativeness of CSR reports in the construction industry are significant lower in the average level of all the industries in China in 2017.

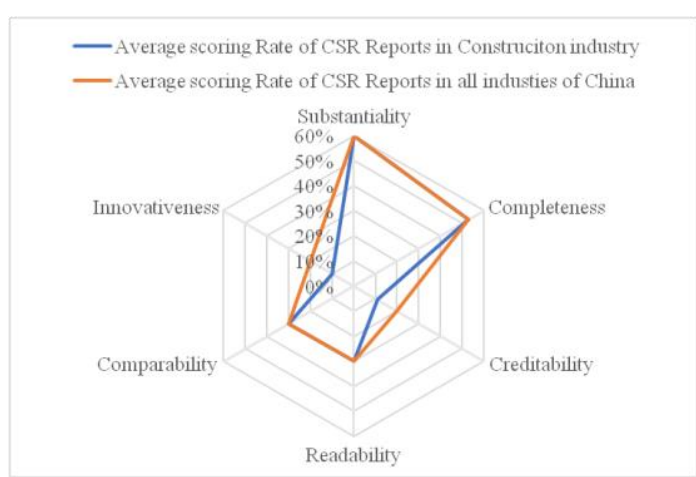

Figure 3 Average Scoring Rate of CSR Reports

There are many environmental issues derived from construction activities such as greenhouse gas emission, waste of resources and damage to the natural environment (Chang et al. 2018).

\section{The dilemma on CER in the construction industry}

\subsection{Legal system}

With the rapidly development of economy and society, China's government is striving to improve the legal system. However, it is not denied that the legal system of China is still weak (Wei et al., 2017). At present, the relevant laws and regulations related to construction industry' environmental practice are relatively abstract and absent from operation. Compared with the current economic, social development and environmental requirement, there are still great gaps. Lack of operable regulations can not guide the construction firms' CER practice. On the other hand, Chinese governments are characterized with multiple levels of administrative hierarchy. Local governments may circumvent the environmental regulations from the central government because of the constrain of the local growth (Wang et al. 2018).

\subsection{Supervision of the construction market}

In the process of diversification of investment in the construction industry, the construction market's regulation is not still standardized. It is a common phenomenon that illegal subcontracting, affiliation and poor project quality. Especially, some poor quality firms do much great harm to the construction market because of the low threshold of the industry market access.

\subsection{Multiple stakeholders}

Aaltonen and Kujala (2016) proposed that the stakeholders of construction are characterized with dynamics, uncertainty, and complexity. Correspondingly, different stakeholders play different roles on CER in construction projects. Governments, as the makers of environmental legal, are the most influential stakeholders on CER; Developers, as the bearer of the 
additional costs, are the deciders of initiating CER. Contractors, as the controllers and coordinators of resources and active in the construction projects, are the practitioners of CER (Lin et al. 2017). Therefore, whether CER can be efficiently implemented does not just depends on the contractors.

In addition, among of the three core stakeholders, contractors are subjects of the construction industries. Compared with developed regions' contractors including European Union, United States and Canada, China's contractors get the lowest scores in implementing CER (Liao et al. 2017). That means China's contractors attitudes on practicing CER is worrying even though governments and developers play their due roles on CER.

\section{Tendency on CER in the construction industry}

\subsection{Perfecting legal system on CER}

Legitimacy and internationalization promote the CER of construction firms. The relative laws and regulations on CER should be enacted to change the situation of unduly decentralization of responsibility legislation. The special legislation of CER provides an incentive mechanism for firms to fulfil their responsibilities. The special legislation should be operable and includes a series of specific system designs on carrying out the CER. In this special legislation, the relationships between environmental responsibility, stockholders, employee, consumers and community should be well coordinated. In addition, China's government should tighten the environmental regulations across sectors and regions (Wang et al., 2018).

\subsection{Enhancing supervision of the market and industry}

The central government of China has established the Ministry of ecological environment to promote the construction of ecological civilization and the modernization of management system in 2018. The ministry will take on the supervision, administration and law enforcement of all kinds of pollution and emission. The supervision institution should encourage the behaviour of optimizing environment and severe punishments in misconducts.

From the view of the construction industry, it should be done to improve the supervision of the internal industry. First, the threshold of entrance to construction industry should be improved by improving the national and provincial assessment standards of construction firms on environmental responsibility. Second, it should be sever published to illegal subcontracting and affiliation. In addition, the open information of construction industry may help to facilitate the supervision of CER in the industry and the information disclosure platform on implementing CER can be constructed by the internet.

\subsection{Strengthening stakeholders' consciousness on CER}

Although the central government highly concerns with the environment, the CER's consciousness of many developers, contractors and other stakeholders in construction industry are still to be improved. Developers play key roles on CER as the deciders of initiating CER. Considering the bargaining cost of advancing CER, some developers choose to evade it. Actually, with the publicity of information and the perfection of the market, the bargaining cost is continuous decline. Furthermore, advocating CER and green buildings may bring long-term profits, for example, Vanke. Contractors are the most crucial actors on CER in the construction industry because they are the practitioners of CER. With the globalization, China's contractors have important influence on the international construction industry (Liao et al. 2017). Implementing CER helps to the contractors obtain legal status and competitive advantage. Therefore, contractors should proactively assume CER. CER strategy should coordinate with practice and integrate into changing economic, social, cultural, environmental profiles (Loosemore and Lim 2018). The key supporting CER strategies in construction industry include strengthening technology innovation, improving standards and evaluation, establishing demonstration projects, and publicity. (Chang et al. 2016).

\section{Conclusions}

Construction industry has bi-directional influences on the economy, society and environment. On the one hand, it has improved national economic level, people's livelihood and social development. On the other hand, it have negative influences on the people's life and natural environment. In order to address the gap that there is little research on CER in Chinese construction industry, the paper clarifies the current situation. Further, the paper analyzes the dilemma and proposes feasible advices on CER in construction industry of China. Some relative CER topics of Chinese construction industry further needs exploring in the future research, such as constructing evaluation system of CER in Chinese construction industry, exploring the antecedent factor of CER, and exploring the influencing mechanism of relationship between the CER and financial performance in construction industry of China.

\section{References}

1. K. Aaltonen and J. Kujala. Towards an Improved Understanding of Project Stakeholder Landscapes. Int. J. Proj. Manag. 34(8), 1537-52 (2016).

2. R. D. Chang, V. Soebarto, Z. Y. Zhao and G. Zillante. Facilitating the Transition to Sustainable Construction: China's Policies. J. Clean. Prod. 131, 534-44 (2016).

3. W. Y. Jiang and J. K. W. Wong. Key Activity Areas of Corporate Social Responsibility (Csr) in the 
Construction Industry: A Study of China. J. Clean. Prod. 113, 850-60 (2016).

4. P. C. Liao, N. N. Xia, C. L. Wu, Zhang. and J. L. Yeh. Communicating the Corporate Social Responsibility (Csr) of International Contractors: Content Analysis of Csr Reporting. J. Clean. Prod. 156, 327-36 (2017).

5. X. Lin, C. M. F. Ho and G. Q. P. Shen. Who Should Take the Responsibility? Stakeholders' Power over Social Responsibility Issues in Construction Projects. J. Clean. Prod. 154, 318-29 (2017).

6. M. Loosemore and B. T. H. Lim. Mapping Corporate Social Responsibility Strategies in the Construction and Engineering Industry. Constr. Manag. Econ. 36(2), 67-82 (2018).

7. W. S. Lu, M. Ye, R. Flanagan and K. H. Ye. Corporate Social Responsibility Disclosures in International Construction Business: Trends and Prospects. J. Constr. Eng. Manag. 142(1),1-14 (2016).

8. L. Y. Shen, Y. Z. Wu and X. L. Zhang. Key Assessment Indicators for the Sustainability of Infrastructure Projects. J. Constr. Eng. Manag. 137(6), 441-51 (2011).

9. R. X. Wang, F. Wijen and H. Pmar. Government's Green Grip: Multifaceted State Influence on Corporate Environmental Actions in China. Strateg. Manag. J. 39(2), 403-28 (2018).

10. Z. L. Wei, H Shen., K. Z. Zhou and J. J Li. How Does Environmental Corporate Social Responsibility Matter in a Dysfunctional Institutional Environment? Evidence from China. J. Bus. Ethics. 140(2), 209-23 (2017). 